\title{
Secondary traumatic stress, dissociative and somatization symptoms in spouses of veterans with PTSD in Zahedan, Iran
}

Mohsen Kianpoor ${ }^{1}$, Parisa Rahmanian², Azizollah Mojahed ${ }^{3}$, Ramin Amouchie ${ }^{4}$

${ }^{1}$ M.D. of Psychiatry, Associate Professor, Zahedan Medical School, Zahedan University of Medical Sciences, Zahedan, Iran

${ }^{2}$ M.Sc. of Clinical Psychology, Zahedan Medical School, Zahedan University of Medical Sciences, Zahedan, Iran

${ }^{3}$ Ph.D. of Clinical Psychology, Faculty Member of Psychology, Zahedan Medical School, Zahedan University of Medical Sciences, Zahedan, Iran

${ }^{4}$ Clinical Psychology, Ph.D. Student, Department of Clinical Psychology, School of Behavior Science, University of Social Welfare and Rehabilitation Sciences, Tehran, Iran

\section{Type of article: Original}

\begin{abstract}
Introduction: Secondary traumatic stress is a disorder which occurs in spouses and people with close relation to someone with posttraumatic stress disorder. Like PTSD, it seems that STS also occurs with other psychiatric problems like somatization and dissociation. This study aimed to determine the relationship between STS and somatization and dissociation symptoms.

Methods: This cross-sectional study was done in 2015 and lasted for one year. Self-report questionnaires assessing secondary traumatic stress symptoms, dissociation symptoms and somatization symptoms were distributed among spouses of veterans with PTSD in Zahedan, Iran. The relationship between STS symptoms and somatization symptoms and also between STS symptoms and dissociation symptoms were determined by Pearson correlation test. SPSS version 23 was used for data analysis.

Results: Occurrence of secondary traumatic stress symptoms were correlated with dissociation symptoms and also with somatization symptoms.

Conclusions: As the rate of secondary traumatic stress rose, the rate of somatization and dissociation symptoms in spouses of veterans increased.
\end{abstract}

Keywords: Secondary Traumatic Stress, Dissociative symptoms, Somatization symptoms

\section{Introduction}

Posttraumatic stress disorder (PTSD) is a psychiatric problem in which people who have experienced a threatening life trauma, may develop its symptoms. Its features may vary in different cases. Its criteria are recurrent involuntary distressing memories and dreams related to trauma, dissociative reactions (e.g. flashbacks), physiological reactions to internal or external signs symbolizing the trauma event, persistent avoidance of stimuli associated with the traumatic event, negative alterations in cognitions and mood associated with the traumatic events and increasing irritability related to trauma (1). One of the most important traumas that may lead to PTSD is war, and it has destructive and longtime consequences for the traumatized individual, his family and his community (2). Mental disease from war will stay with veterans for many years after war (3). Research has shown that about $30 \%$ of Vietnam War veterans visited the criteria of PTSD and 25\% of veterans showed its clinical symptoms. These veterans problems led to complications in playing their roles as a father or husband (4). There are no clear statistics about the rate of PTSD among veterans of the Iran-Iraq war. After the Iran-Iraq war, which lasted for 8 years, a large number of individuals in various parts of Iran suffered from numerous problems (5). Many researches have shown greater incidence of mental problems in their families, than fathers who were non veterans. (6). Since the spouse is

\section{Corresponding author:}

Parisa Rahmanian, Zahedan Medical School, Zahedan University of Medical Sciences, Zahedan, Iran.

Tel: +989365164347, Fax: +98.7143330776, Email: parisarahmanian88@gmail.com

Received: August 30, 2016, Accepted: December 17, 2016, Published: April 2017

iThenticate screening: November 16, 2016, English editing: January 23, 2017, Quality control: February 02, 2017

(C) 2017 The Authors. This is an open access article under the terms of the Creative Commons Attribution-NonCommercialNoDerivs License, which permits use and distribution in any medium, provided the original work is properly cited, the use is non-commercial and no modifications or adaptations are made. 
the closest person to the veteran, the first person who would be influenced by a veteran's mental problems is his wife (7). Researches have shown that in these veteran's families, violence and physical and verbal aggression to their spouses is more prevalent than in normal families (8). Spouses of veterans with PTSD have many problems to adjust with their husbands' symptoms such as their inappropriate requests, physical aggression and emotions, and these factors may lead to mental problems (9). Caregivers, nurses, family members and anyone who has a direct and close relationship with patients with PTSD may begin to cumulate the experiences of their patient's trauma (10). Many various investigations indicate that spouses of veterans with PTSD, express symptoms like the PTSD symptoms of their husband (7). These symptoms, in different sources, have different names such as caregiver burden, compassion fatigue, vicarious traumatization, and is also called secondary traumatic stress (STS) as Figley noted for the first time (11). These symptoms are similar to PTSD except that people with PTSD have experienced direct trauma whereas people with STS haven't (12). The mechanism of the transmission of the PTSD's symptoms to a close caregiver is still almost unclear (13). In trauma transmission model of Figley, the family is a system, and members of the system try to empathize with the victim of the trauma and his sufferings. In this process, family members imagine trauma experiences and experience victim emotions (14). As Koic et al. noted in their research, 33\% of spouses of veterans with PTSD have STS symptoms (15). Franciskovich et al. found in their research that $37 \%$ of spouses of veterans with PTSD suffer from STS (13). Also, in Iran, as Pourafshar et al. reported there was $49 \%$ to $51 \%$ of STS symptoms among caregivers of patients with PTSD (16). Another study in Sardasht, Iran, investigated that the total number of PTSD in spouses of veterans was significantly higher than normal women without a veteran husband (17). A study in Tehran, Iran, also investigated that the mean number of STS in spouses of veterans with PTSD was 55.70 (16). Authors couldn't find a research in Zahedan about STS in spouses of veterans, however, in a research done in Zahedan, mental health problems in spouses of veterans with PTSD was significantly higher in comparison with spouses of veterans without PTSD (18). So in this study we want to investigate the STS in spouses of veterans in Zahedan. PTSD is a mental problem, which rarely occurs alone and usually occurs with other mental problems. About $50 \%$ to $90 \%$ of patients with chronic PTSD have one or more psychiatric problems. As noted that STS symptoms are similar to PTSD, maybe some psychiatric problems which occur with PTSD also occur with STS. The relationship between trauma and dissociation and also between trauma and somatization is clear in many past researches (19). Many different researches have shown a strong relationship between trauma and dissociative symptoms $(20,21)$. Dissociation is the main characteristic of dissociative disorders, and is defined as separating the mental processes that were consistent in normal cases. This symptom may be a reflection of an adjustment process with stress. Dissociative defense may develop, to help the traumatized person to adjust the traumatic event. Dissociative mechanisms may change perceptions (Depersonalization/ Derealization disorder), let the person forget (Dissociative amnesia), or completely deny the experience as it has occurred for the other person (Dissociative identity disorder) (22). Many researches have noted that there is an increase in reported somatic complaints among people with PTSD (23). People with somatization usually have different somatic symptoms that are considerably troubling. Symptoms may be specific (e.g. local pain), or can be unspecific (e.g. fatigue). People with somatization tend to have a lot of worries about their illness. They evaluate their somatic symptoms as very threatening or destructive. Psychoanalyzes explain somatization as an unconscious process that leads to using inappropriate defense. These patients use their somatic symptoms to show their emotional problems. Some researches indicated that people with somatization symptoms tend not to express their emotions. Expressing emotions means wanting to share the emotions with others (24). It may be the reason why some people who have experienced a trauma, develop somatization symptoms. The aim of this study was to determine the relationship between STS and dissociation and somatization symptoms.

\section{Material and Methods}

This cross-sectional, analytic study was done in 2015 among spouses of veterans with combat related PTSD living in Zahedan city in Iran. There are foundations in all cities of Iran where all the veterans from the war between Iran and Iraq (1980-1988) have a file. In these foundations, veteran files have been divided according to their injuries in war (e.g. chemical veterans, PTSD veterans). There were 50 names in the given list. We called all the numbers in the list. After explaining the goals of the research, 40 spouses agreed to participate in our research. Three wives were omitted because their husbands were deceased. Then a time was set and we visited their homes. Because most of the women didn't have adequate education, the questionnaire was read to them before they signed consent.

\subsection{Participants}

Forty spouses of veterans with PTSD symptoms were administered a questionnaire regarding occurrence of secondary traumatic stress symptoms and their relationship to dissociative symptoms and somatization symptoms. There were 50 families in the list of veterans in the foundation. Three of the veterans were deceased and seven wives 
didn't agree to participate in the research. Forty women accepted participation in the research. Their husbands participated in the Iran and Iraq war from 1980-1988 and had received diagnosis of PTSD relating to their files. The average of the women's age was 45.24 .

\subsection{Assessments}

To assess secondary traumatic stress symptoms, secondary traumatic stress scale was used. This is a 17 -item selfreport scale which is made by Bride et al. in 2004. The respondents are asked to answer on a 5-point Likert scale to rate the extent to which they had experienced in the past week. The score 38 and more, shows that there is a disorder (25). To assess somatization symptoms, Somatoform Dissociation Questionnaire (SDQ- 20) was used. This is a 20item self-report scale, made by Nijenhuis et al. in 1996. The respondents answered their experiences on a 5- point Likert scale. The cut off point for this scale is 25 (26). Dissociative symptoms were assessed with the Dissociative Experience Scale (DES), made by Carlson and Putnam in 1992. DES is a 28-item self-report measure to assess these types of dissociation experiences: Depersonalization/ Derealization, Amnestic Dissociation, Absorption and Imaginative involvement. The respondents are asked to rate their dissociative experiences from $0 \%$ to $100 \%$. The average number of 30 or more show high dissociation but not pathological (27).

\subsection{Statistical methods}

In this study, 40 spouses of veterans with PTSD were measured. Correlation of STS symptoms with dissociative and somatization symptoms were measured by Pearson correlation. The statistical package for social sciences, SPSS 23 for Windows was used.

\section{Results}

The mean of women's age was 45.24. According to the percentage of education rate, $62.5 \%$ of them had cycle, $27.5 \%$ had diploma and $10 \%$ had bachelor. In this statistic population, $67.5 \%$ of the respondents met the criteria for STS according to cut point of STSS, $64.86 \%$ of them had a high severity dissociation according to cut point of DES, and $27.02 \%$ of them met criteria for somatization according to cut point of SDQ. Women's mean total sum of STS in STSS was 46.37, the mean total sum of dissociation according to DES was 64.64, and the mean total sum of somatization according to SDQ was 14.67. Regarding data analysis, there was a statistically significant correlation between secondary traumatic stress symptoms and dissociation symptoms among spouses of veterans with combat related PTSD, and correlation coefficient was $0.532(\mathrm{p}<0.01)$. There was also a statistically significant correlation between secondary traumatic stress symptoms and somatization symptoms among them, and correlation coefficient was $0.449(\mathrm{p}<0.01)$.

\section{Discussion}

As many past researches assessed, there is a strong relationship between PTSD and dissociation symptoms (20), (21). As the symptoms of STS are similar to PTSD's symptoms, existence of a relationship between STS and dissociation similar to PTSD and dissociation seems reasonable. As our research investigated, there is a statistically significant relationship between STS and dissociation in spouses of veterans with PTSD. There are many explanations for this relationship. One explanation is that dissociation defense expands to help people adjust with traumatic events (22). These women have experienced their husband's trauma indirectly and imaginary, and also, they don't know how to cope with their new symptoms, so it is possible they have used dissociative defense to adjust to these symptoms. These women have many more responsibilities than women with normal lives, and most of them do not receive enough social and family support. Most of them had low education and were unemployed. Lack of support, low education and unemployment are negative factors for learning strategies to adjust with their problems. So as Janet's model says that dissociation is a strategy for coping with stressful events in their life, it seems that these women haven't learned useful coping strategies and unconsciously expand dissociative symptoms to adjust with their problems. Also in our research, it was found that there is a statically significant correlation between STS and somatization among spouses of veterans with PTSD. This result is similar to the relationship between PTSD and somatization as was noted in past researches $(19,20,23,28)$. These women are expected to handle their stressful lives, their children and their sick husbands. These negative experiences may cause negative emotions and lead to many mental problems. Without enough help and support, they feel isolated and can't share their negative emotions with others. And on the other hand, expressing physical problems is culturally more acceptable and easier than expressing mental problems. So it seems that these women can't express their negative emotions and mental problems, so they express their problems as somatic symptoms. 


\section{Conclusions}

It seems that the women living with veterans for a number of years, have developed different symptoms like STS, dissociation and somatization. As the STS symptoms are similar to PTSD symptoms, some comorbid psychiatric problems with PTSD like dissociation and somatization, also seem to be comorbid with STS. There were significant relationships between STS, dissociation symptoms and somatization symptoms. These results mean that veteran's women need serious attention and social support, because their mental problems are equally as serious as their husbands.

\section{Acknowledgments:}

This article has been extracted from the thesis written by Parisa Rahmanian MSC of Clinical Psychology, Zahedan University of Medical Sciences. Special thanks to Zahedan University of Medical Sciences for cooperation with authors. The authors would like to thank the families of veterans with PTSD in Zahedan for their cooperation in this research.

\section{Conflict of Interest:}

There is no conflict of interest to be declared.

\section{Authors' contributions:}

All authors contributed to this project and article equally. All authors read and approved the final manuscript.

\section{References:}

1) Friedman MJ, Resick PA, Bryant RA, Brewin CR. Considering PTSD for DSM - 5. Depress Anxiety. 2011; 28(9): 750-69. doi: 10.1002/da.20767. PMID: 21910184.

2) Flannery R. Post-traumatic stress disorder: The victim's guide to healing and recovery: Lantern Books; 2012.

3) Anisi J. The study of mental status of neuropsycho veteran wives in comparison with non neuro psycho veteran wives MA dissertation. Allameh Tabatabaii University. 1998.

4) Sherman MD, Zanotti DK, Jones DE. Key Elements in Couples Therapy With Veterans With CombatRelated Posttraumatic Stress Disorder. Professional Psychology. Research and Practice. 2005; 36(6): 626. doi: 10.1037/0735-7028.36.6.626.

5) Afkar A, Mahboubi M, Shahri MN, Mohamadi M, Jalilian F, Moradi F. Investigation of the Relationship between Illogical Thoughts and Dependence on Others and Marriage Compatibility in the Iranian Veterans Exposed to Chemicals in Iran-Iraq War. Global journal of health science. 2014; 6(5): 38-45. doi: 10.5539/gjhs.v6n5p38. PMID: 25168982, PMCID: PMC4825379.

6) Calhoun PS, Beckham JC, Bosworth HB. Caregiver burden and psychological distress in partners of veterans with chronic posttraumatic stress disorder. J Trauma Stress. 2002; 15(3): 205-12. doi: 10.1023/A:1015251210928. PMID: 12092912.

7) Taft CT, Niles BL. Assessment and treatment of anger in combat related PTSD. Iraq war clinician's guide Boston: Department of Veterans Affairs, National Center for PTSD. 2004.

8) Jordan BK, Marmar CR, Fairbank JA, Schlenger WE, Kulka RA, Hough RL, et al. Problems in families of male Vietnam veterans with posttraumatic stress disorder. J Consult Clin Psychol. 1992; 60(6): 916-26. doi: 10.1037/0022-006X.60.6.916. PMID: 1460153.

9) Nelson BS, Wright DW. Understanding and treating post - traumatic stress disorder symptoms in female partners of veterans with ptsd. Journal of Marital and Family Therapy. 1996; 22(4): 455-67. doi: 10.1111/j.1752-0606.1996.tb00220.x.

10) Zimering R, Gulliver SB, Knight J, Munroe J, Keane TM. Posttraumatic stress disorder in disaster relief workers following direct and indirect trauma exposure to Ground Zero. J Trauma Stress. 2006; 19(4): 5537. doi: 10.1002/jts.20143. PMID: 16929511.

11) McCann IL, Pearlman LA. Vicarious traumatization: A framework for understanding the psychological effects of working with victims. Journal of traumatic stress. 1990; 3(1): 131-49. doi:10.1007/BF00975140.

12) Stamm B. Secondary traumatic stress: Self-care issues for clinicians, researchers, and educators: The Sidran Press; 1995.

13) Frančišković T, Stevanović A, Jelušić I, Roganović B, Klarić M, Grković J. Secondary traumatization of wives of war veterans with posttraumatic stress disorder. Croat Med J. 2007; 48(2): 177-84. PMID: 17436382, PMCID: PMC2080512. 
14) Deering D. Compassion Fatigue: Coping With Secondary Traumatic Stress Disorder In Those Who Treat the Traumatized. Journal of Psychosocial Nursing and Mental Health Services. 1996; 34(11): 52.

15) Koić E, Francišković T, Mužinić-Masle L, Đorđević V, Vondraček S, Prpić J. Chronic pain and secondary traumatization in wives of Croatian war veterans treated for post traumatic stress disorder. Acta clin Croat. 2002; 41(4): 295-306.

16) Abolmaali Kh, Aghaeepoor M. Effectiveness of Cognitine-Behavioral Training on Reducing the Secondary Trauma Symptoms of PTSD Veteran's Wives. Iran J War Public Health. 2015; 7(2): 57-65.

17) Ahmadi Kh, Reshadatjou M, Karami GR, Anisi J. Vicarious ptsd in sardasht chemical warfare victims'wives. Journal of behavioral sciences. 2009; 3(3): 195-9.

18) Bakhshani N, Shakiba M, Mojahed A, Kalantari M, Molavi H, Neshat-doost H. Comparative investigation of mental health status of spouses of war handicaps in accordance with husband's disability. ZJRMS. 2010; 12(4): 38-42.

19) Saxe GN, Chinman G, Berkowitz R, Hall K, Lieberg G, Schwartz J, et al. Somatization in patients with dissociative disorders. Am J Psychiatry. 1994; 151(9): 1329-34. doi: 10.1176/ajp.151.9.1329. PMID: 8067489.

20) Van der Kolk BA, Pelcovitz D, Roth S, Mandel FS, McFarlane A, Herman JL. Dissociation, somatization, and affect dysregulation: the complexity of adaptation of trauma. Am J Psychiatry. 1996; 153(7 Suppl): 83 93. doi: 10.1176/ajp.153.7.83. PMID: 8659645.

21) Kulkarni M, Porter KE, Rauch SA. Anger, dissociation, and PTSD among male veterans entering into PTSD treatment. J Anxiety Disord. 2012; 26(2): 271-8. doi: 10.1016/j.janxdis.2011.12.005. PMID: 22245698.

22) Walker EA, Katon WJ, Neraas K, Jemelka RP, Massoth D. Dissociation in women with chronic pelvic pain. Am J Psychiatry. 1992; 149(4): 534-7. doi: 10.1176/ajp.149.4.534. PMID: 1554041.

23) McFarlane AC, Atchison M, Rafalowicz E, Papay P. Physical symptoms in post-traumatic stress disorder. J Psychosom Res. 1994; 38(7): 715-26. doi: 10.1016/0022-3999(94)90024-8. PMID: 7877126.

24) Gross JJ, John OP. Facets of emotional expressivity: Three self-report factors and their correlates Personality and individual differences. 1995; 19(4): 555-68. doi: 10.1016/0191-8869(95)00055-B.

25) Ahmadi K, Rezapour Y, Davoudi F, Saberi M. Investigate of Validity and Reliability of Secondary Trauma Stress Scale for Evaluation of PTSD Symptoms in Samples of Warfare Victims' Wives. Iran J War Public Health. 2013; 5(3): 47-57.

26) Nijenhuis E. The scoring and interpretation of the SDQ-20 and SDQ-5. ANS: The Journal for 26. Neurocognitive Research. 2010; 52.

27) Carlson E, Putnam F. Manual for the dissociative experiences scale. Unpublished manuscript, Department of Psychology, Beloit College, Beloit, WI. 1992.

28) Yambo T, Johnson M. An integrative review of the mental health of partners of veterans with combatrelated posttraumatic stress disorder. J Am Psychiatr Nurses Assoc. 2014; 20(1): 31-41. doi: 10.1177/1078390313516998. PMID: 24441511. 